\title{
Como a deficiência afeta a educação e o trabalho de jovens no Brasil
}

\author{
How disability affects the schooling and labor of the youngsters in Brazil
}

Kalinca Léia Becker (1)

(1) Universidade Federal de Santa Maria

\begin{abstract}
This study aims to analyze how discrimination and activity limitations caused by disability may affect both education and work of young people aged 15 to 24 years old. In order to do so, the data from the National Health Survey of 2013 as well as the Multinomial Logit Model were used to calculate the probabilities of having young people studying, working or looking for a job. The results showed that disability, particularly intellectual disability, usually contributes to decreasing school attendance and participation in the labor market. However, some exceptions have been observed, such as in the case of visually impaired and physically disabled young people without limitations in performing usual activities who are, therefore, more likely to work. In addition, men who are hearing impaired and show activity limitations are more likely to study. These results may be related with special education policies and job quotas for people with disabilities.
\end{abstract}

\section{Keywords}

disability, economic of people with disabilities, work, education.

JEL Codes J14, I24, I38.

\section{Resumo}

O objetivo deste estudo é analisar como a discriminação e as limitações das atividades causadas pela deficiência podem afetar a educação e o trabalho dos jovens com idade entre 15 e 24 anos. Para isso, utilizaram-se os dados da Pesquisa Nacional de Saúde de 2013 e um modelo logit multinomial para estimar as probabilidades de o jovem estudar/ trabalhar/ procurar emprego. Os resultados indicaram que, de maneira geral, a deficiência contribui para diminuir a frequência escolar e a participação no mercado de trabalho, principalmente no caso da deficiência intelectual. Algumas exceções foram observadas, como no caso dos jovens com deficiência visual e com deficiência física sem limitações das atividades habituais, que apresentam maior probabilidade de trabalhar. Os homens com deficiência auditiva e limitações das atividades habituais apresentam maior probabilidade de estudar. Esses resultados podem estar associados às políticas de educação especial e de cotas de emprego para pessoas com deficiência.

\section{Palavras-chave}

deficiência, economia das pessoas com deficiência, trabalho, educação.

Códigos JEL J14, I24, I38. 


\section{Introdução}

"A deficiência não precisa ser um obstáculo para o sucesso". Assim, o Professor Stephen Hawking, astrofísico e portador de uma doença do neurônio motor, iniciou o preâmbulo do Relatório Mundial sobre Deficiência da Organização Mundial da Saúde, OMS (2011).

O modelo de "síntese biopsicossocial" de análise e definição da deficiência, formalizado pela OMS (2013), reconhece que a participação econômica e social das pessoas com deficiência depende tanto das condições de saúde como também do ambiente físico, social e operacional no qual essas pessoas estão inseridas. Dessa forma, nesse último caso, a participação das pessoas com deficiência irá depender de como a sociedade lida com essa condição, abrangendo a questão da discriminação e também do comprometimento e reconhecimento da necessidade de fornecer infraestrutura, produtos, tecnologias, serviços e políticas públicas direcionadas a essa população.

Porém, conforme as informações do Relatório da OMS (2011), a humanidade ainda está muito aquém no processo de fornecer as condições de igualdade para a participação econômica e social das pessoas com deficiência. Com base na análise das informações de 51 países, observados da Pesquisa Mundial de Saúde de 2002-2004 (WHO World Health Survey), ${ }^{1}$ o relatório indicou que $50,6 \%$ dos homens com deficiência concluíram a escola primária, em comparação com $61,3 \%$ dos homens sem deficiência. No caso das mulheres com deficiência, 41,7\% concluíram a escola primária, em comparação com 52,9\% das mulheres sem deficiência. A média de anos de escolaridade é igualmente inferior para as pessoas com deficiência em comparação com as pessoas sem deficiência (homens: 5,96 e 7,03 anos, mulheres: 4,98 e 6,26 anos, respectivamente). Além disso, as diferenças na conclusão da educação são observadas em todas as faixas de idade, tanto nos países de alta renda como de baixa renda, embora a diferença seja mais pronunciada nestes últimos. No mercado de trabalho, as pessoas com deficiência recebem, em média, menores salários, e as taxas de emprego para essas pessoas são menores em $53 \%$ para homens e em $20 \%$ mulheres, em comparação com as pessoas sem deficiência.

Nesse sentido, Filmer (2008) analisou informações de pessoas com de- 
ficiência em 13 países em desenvolvimento ${ }^{2}$ e observou que, em média, cerca de 1 a $2 \%$ da população apresenta alguma deficiência. Os adultos com deficiência, geralmente, vivem em famílias mais pobres, porém grande parte dessa relação parece ser explicada pelo fato de que essas pessoas têm, em média, menor nível de escolaridade. Conforme evidenciado por Cunha et al. (2006), o nível educacional de um indivíduo é resultado de um processo de acúmulo de capital humano que ocorre ao longo do ciclo de vida. Dessa forma, as oportunidades de acesso à educação, qualificação e experiência profissional concedidas aos jovens são essenciais para a formação do capital humano, de modo que restrições a essas oportunidades podem estar associadas à pobreza de longo prazo.

Em economia, muitas pesquisas que tentam explicar as decisões de alocação do tempo dos jovens baseiam-se no modelo teórico proposto por Becker (1993), no qual os indivíduos maximizam a sua utilidade a partir do consumo de bens, serviços e lazer, sujeito as restrições de tempo e de renda. Nesse modelo, o tempo é distribuído entre trabalho, lazer e educação. Embora o lazer seja considerado preferível ao trabalho, implica menos renda para consumir bens de mercado. A educação é vista como um bem de investimento que gera custos presentes, relacionados à quantidade de bens de consumo a que se deve renunciar, porém gera benefícios futuros, obtidos através da remuneração adicional de um maior nível de instrução.

No caso das pessoas com deficiência, a condição de saúde pode ser incorporada ao modelo através da restrição de tempo, quando as limitações causadas pela deficiência reduzem o tempo disponível para as demais atividades, e também através da restrição orçamentária, quando a oferta de trabalho e a remuneração das pessoas com deficiência é menor em consequência da discriminação ou da menor produtividade imposta pelas condições de saúde (Jones et al. 2006). Vale ressaltar que a menor produtividade e o menor tempo disponível podem ser uma consequência específica da deficiência, mas também podem estar relacionados a indisponibilidade de infraestrutura, serviços e recursos adequados. Dessa forma, os jovens com deficiência enfrentariam restrições adicionais de participação na sociedade, em desacordo com o ideal de igualdades de condições, estabelecido pela ONU (Brasil, 2009).

2 Bolívia, Camboja, Chade, Colômbia, Índia, Jamaica, România, Burundi, Mongólia, Indonésia, Moçambique, África do Sul e Zâmbia. 
Diante disso, este estudo buscou analisar como a discriminação e as limitações das atividades causadas pela deficiência podem afetar a educação e o trabalho dos indivíduos com idade entre 15 e 24 anos, uma vez que as restrições às oportunidades concedidas aos jovens afetam a sua formação e, assim, prejudicam a futura capacidade de inserção no mercado do trabalho, o que pode gerar pobreza no longo prazo. Dessa forma, foram estimadas as probabilidades de o jovem estudar/trabalhar/procurar emprego através de um modelo logit multinomial. Os dados são da Pesquisa Nacional de Saúde (PNS) de 2013, que permite identificar as pessoas com deficiência intelectual, física, auditiva e visual e se essa condição causa limitações das atividades habituais.

Supondo que os jovens cuja deficiência não traz limitações têm a mesma capacidade de inserção no mercado de trabalho e nas atividades acadêmicas dos jovens que não possuem deficiência, uma possível menor probabilidade estimada de estudar/trabalhar/procurar emprego dos jovens com deficiência sem limitações pode ser interpretada como uma estimativa de discriminação. Desse modo, o efeito das limitações causadas pela deficiência pode ser separado da discriminação (Jones et al. 2006). Os resultados desse estudo podem contribuir para orientar políticas direcionadas para promover a participação econômica e social das pessoas com deficiência.

\section{Revisão bibliográfica}

Esta seção contempla uma breve descrição do conceito de deficiência, com o intuito de embasar os conceitos de discriminação e limitações das atividades causadas por essa condição, e também um resumo das principais políticas, instituições e ações direcionadas ao atendimento de pessoas com deficiência, que podem contribuir para a inserção econômica e social dessa população.

\subsection{Conceito de deficiência}

Conforme o Relatório da Organização Mundial da Saúde (OMS, 2011), deficiência é um conceito complexo, dinâmico, multidimensional e controverso. A forma como, institucionalmente, se define a deficiência impacta 
diretamente na formulação das políticas públicas e na interação e tratamento dessas pessoas na sociedade. Existem dois modelos principais para a conceituação e definição da deficiência.

O primeiro é o modelo médico, que define a deficiência como perda ou anormalidade de estrutura ou função psicológica, fisiológica ou anatômica, temporária ou permanente. Incluem-se nessas a ocorrência de uma anomalia, defeito ou perda de um membro, órgão, tecido ou qualquer outra estrutura do corpo, inclusive das funções mentais. Representa a exteriorização de um estado patológico, refletindo um distúrbio orgânico, uma perturbação no órgão (Amiralian et al., 2000).

Dessa forma, no modelo médico, a deficiência é entendida como uma experiência do corpo que deve ser superada com tratamentos na área da saúde, de modo que a cura completa seria a condição ideal para que pessoas com deficiência possam exercer seus direitos e participar plenamente na sociedade (Werneck, 2004).

Uma alternativa para o modelo médico, denominada de modelo social, começou a ser desenvolvida por cientistas sociais e da saúde e, também, por iniciativa de pessoas com deficiência que se organizaram no Movimento Social da Deficiência (Social Disability Movement), realizado no Reino Unido nos anos 60 (Charlton, 1998). Conforme Werneck (2004), esse movimento procurou mostrar como a maior parte das dificuldades enfrentadas por pessoas com deficiência é resultado da forma pela qual a sociedade lida com as limitações e as lesões físicas, intelectuais, sensoriais e múltiplas de cada indivíduo.

Assim, a percepção do modelo social é que a deficiência é sempre uma construção coletiva entre indivíduos e sociedade e atribui as desvantagens individuais e coletivas das pessoas com deficiência principalmente à discriminação institucional. Werneck (2004) ressalta ainda que adotar o paradigma do modelo social não pressupõe o abandono da reabilitação e dos tratamentos médicos, embora esses tratamentos, ainda que importantes, não devam se sobrepor à garantia de educação, emprego, cultura, lazer e vida independente para as pessoas com deficiência.

O Relatório da OMS (2011) destaca que, embora o modelo médico e o modelo social sejam frequentemente apresentados como dicotômicos, a deficiência não deve ser vista como puramente médica ou como puramente social, uma vez que as pessoas com deficiência podem ter problemas decorrentes de sua condição de saúde. Dessa forma, é necessária uma 
abordagem equilibrada, dando um peso adequado aos diferentes aspectos da deficiência.

Nesse sentido, a Classificação Internacional de Funcionamento, Deficiência e Saúde (Internacional Classification of Functioning, Disability and Health - ICF), da Organização Mundial da Saúde (OMS, 2013), busca integrar os dois modelos de deficiência através de uma "síntese biopsicossocial", de modo que o conceito de deficiência busca abranger aspectos da "interação dinâmica entre a condição de saúde de uma pessoa, fatores ambientais e fatores pessoais", a partir de uma perspectiva biológica, individual e social (OMS, 2013).

Por essa classificação, define-se atividade como a execução de uma tarefa ou ação por um indivíduo, de modo que as limitações da atividade são as dificuldades que um indivíduo pode enfrentar na execução dessas atividades, por exemplo, caminhar ou comer. Além disso, define-se a participação como o envolvimento em uma situação de vida, de modo que as restrições de participação são os problemas que um indivíduo pode experimentar no envolvimento nessas situações, por exemplo, discriminação no emprego.

Os fatores ambientais referem-se ao ambiente físico, social e operacional em que as pessoas vivem e conduzem suas vidas. Esses fatores podem ser tanto barreiras como também facilitadores do funcionamento e das atividades da pessoa. Incluem: produtos e tecnologias, ambiente natural e construído, apoio e relacionamentos, atitudes, serviços, sistemas e políticas. Exemplos: intérprete de libras, elevadores, computadores adaptados.

Já os fatores pessoais são intrínsecos ao indivíduo, como motivação e autoestima, que podem influenciar o quanto uma pessoa participa da sociedade. No entanto, esses fatores ainda não são conceituados ou classificados.

\subsection{Políticas públicas para pessoas com deficiência}

A Declaração Universal dos Diretos Humanos, da Organização das Nações Unidas (ONU), 1948, ${ }^{3}$ foi um marco inicial no entendimento de que todo ser humano tem direito a participação social. Porém, após aproxima-

3 Adotada e proclamada pela resolução 217 A (III) da Assembleia Geral das Nações Unidas em 10 de dezembro de 1948. Disponível em: http://unesdoc.unesco.org/ images/0013/001394/139423por.pdf. 
damente seis décadas da publicação dessa Declaração, em quase todo o mundo, as pessoas com deficiência são menos propensas a iniciar a vida escolar, apresentam menores taxas de permanência e aprovação na escola, estão mais suscetíveis a desemprego, a pobreza e a menor remuneração (OMS, 2011).

Diante disso, as organizações internacionais têm atuado no sentido de conscientizar os países a investir recursos e promover políticas para garantir os diretos e a participação social das pessoas com deficiência, através de documentos como Convenção Interamericana para a Eliminação de Todas as Formas de Discriminação contra as Pessoas Portadoras de Deficiência, Brasil (2001), e a Convenção sobre os Direitos das Pessoas com Deficiência, Brasil (2009).

Muitos países têm incluído na legislação medidas para garantir a empregabilidade de pessoas com deficiência, como o Americans with Disabilities Act (ADA), promulgado em 1990 nos Estados Unidos, e o Disability Discrimination Act (DDA), promulgado em 1996 na Inglaterra. Porém, muitos estudos apontam que essas medidas não estão, necessariamente, produzindo os resultados esperados (Schwochau; Blanck, 2000; Jones, 2008; Bell e Heitmueller, 2009). Acemoglu e Angrist (2001) observaram uma queda acentuada no emprego dos trabalhadores com deficiência após o ADA entrar em vigor, principalmente em empresas de médio porte e em estados com maior número de acusações de discriminação relacionados com o ADA. No caso do DDA, Jones et al. (2006) evidenciaram que as diferenças de empregabilidade e de salário continuam a existir, principalmente no caso de trabalhadores com problemas de saúde mental.

Medidas para garantir o acesso à educação de pessoas com deficiência também integram a legislação de muitos países. Hanushek et al. (2002) evidenciou que, embora as informações sejam escassas, o Individuals with Disabilities Education Act (IDEA), promulgado em 1975 nos Estados Unidos, parece ter proporcionado o acesso à educação em escolas públicas para um grande número de crianças com deficiência que, até então, eram excluídas do sistema educacional.

A legislação brasileira, seguindo a tendência mundial, tem avançado no sentido de promover, em condições de igualdade, o exercício das liberdades fundamentais da pessoa com deficiência, assegurando o direito a educação e a inclusão no trabalho (Brasil, 2015a). A instituição responsável por atuar na articulação e coordenação das políticas públicas, voltadas para 
as pessoas com deficiência, é a Secretaria Nacional de Promoção dos Direitos da Pessoa com Deficiência (SNPDP), integrante da Secretaria de Direitos Humanos da Presidência da República. Uma de suas competências é coordenar ações de prevenção e eliminação de todas as formas de discriminação contra a pessoa com deficiência e propiciar sua plena inclusão à sociedade. O Conselho Nacional dos Direitos da Pessoa com Deficiência (Conade) é responsável por acompanhar e avaliar o desenvolvimento de uma política nacional para inclusão da pessoa com deficiência e das políticas setoriais de educação e trabalho, entre outros.

No caso específico da educação, o órgão responsável pela definição da política para a Educação Especial e Inclusiva é a Diretoria de Políticas de Educação Especial, vinculada à Secretaria de Educação Continuada, Alfabetização, Diversidade e Inclusão (Secadi) do Ministério da Educação (MEC). O Ministério também integra o Instituto Nacional de Educação de Surdos (Ines), centro de referência na área da surdez que atua no desenvolvimento e divulgação de conhecimentos científicos e tecnológicos nessa área, e o Instituto Benjamin Constant (IBC), um centro de referência para questões da deficiência visual que atua na educação de crianças e adolescentes, desenvolve cursos de capacitação profissional nessa área, além de pesquisas médicas no campo da oftalmologia.

As teorias e práticas baseadas no princípio da educação inclusiva começaram a ser discutidas com maior ênfase no Brasil concomitantemente ao sistema de proteção social, promovido pela Constituição Federal de 1988. Dessa forma, a Política Nacional de Educação na Perspectiva da Educação Inclusiva estabelece a "transversalidade da educação especial desde a educação infantil até a educação superior" (Brasil, 2008). Uma das metas do Plano Nacional de Educação é universalizar, para a população de 4 a 17 anos com deficiência, o acesso à educação básica e ao atendimento educacional especializado, preferencialmente na rede regular de ensino (Brasil, 2015b). Na educação superior, o Decreto $n^{\circ} 7.611 / 2011$ estabelece medidas para eliminar barreiras físicas de comunicação e de informação que restringem a participação e o desenvolvimento acadêmico e social de estudantes com deficiência (Brasil, 2011).

Com isso, as matrículas de alunos especiais em classes comuns do ensino regular apresentaram um crescimento de 640\% entre 1998 e 2006, passando de 43.923 alunos em 1998 para 325.316 em 2006 (Brasil, 2008). Em 2013, 85,5\% dos alunos com necessidades especiais de 4 a 17 anos 
de idade estavam matriculados em classes comuns do ensino regular e/ou Educação de Jovens e Adultos (EJA) da educação básica, ou seja, 546.876 de alunos do total de 639.888 matrículas dessa população (Brasil, 2015b).

Porém, Mendes (2010) destaca que os desafios da educação especial brasileira não se limitam ao acesso, pois os alunos que são o público-alvo dessas políticas não estão, necessariamente, recebendo uma educação apropriada, seja por falta de profissionais qualificados ou mesmo pela falta generalizada de recursos. Nesse mesmo sentido, Meletti e Bueno (2011) argumentam que o crescimento do número de matrículas do público-alvo da educação especial em classes regulares sem qualquer tipo de apoio revela uma preocupação direcionada apenas para o aumento quantitativo dessas matrículas, deixando a desejar em relação à qualidade do ensino ofertado. Meletti e Ribeiro (2014) acrescentam ainda que as matrículas de alunos público-alvo da educação especial na educação básica concentram-se nas primeiras séries do ensino fundamental, com ampla defasagem idade/série. No ensino superior, Martins et al. (2015) evidenciam que os alunos com deficiência efetivamente matriculados representam uma camada mínima em relação ao total da população.

Já no caso da inclusão no mercado de trabalho, o Artigo 37 do Decreto $n^{\circ} 3.298 / 1999$ estabelece que a pessoa portadora de deficiência tem o direito de se inscrever em concurso público, sendo reservado no mínimo $5 \%$ em face da classificação obtida (Brasil, 1999). O Artigo 93 da Lei n 8.213/1991 estabelece que a empresa com 100 ou mais empregados deve preencher de $2 \%$ a $5 \%$ dos seus cargos com beneficiários reabilitados ou pessoas portadoras de deficiência, na seguinte proporção: $2 \%$ até 200 empregados, 3\% de 201 a 500, 4\% de 501 a 1.000 e 5\% de 1.001 em diante (Brasil, 1991).

Porém, conforme o estudo de Neri (2003), a empregabilidade média observada das pessoas com deficiência foi, respectivamente, $2,7 \%$ em empresas com até 200 empregados, 2,9\% com 201 a 500, 2,8\% com 501 a 1.000 e 3,6\% com 1.001 em diante. Além disso, as chances de encontrar uma pessoa com deficiência com as mesmas características trabalhando em empresas com menos de 100 empregados é duas vezes maior do que em empresas com mais de 1.000 trabalhadores. Ribeiro e Carneiro (2009) analisaram os processos de autuação por não cumprimento da lei de cotas para deficientes em Belo Horizonte entre 2000 e 2007 e observaram que existe seletividade nas contratações, uma vez que essas priorizam deficiente físico não cadeirante, em detrimento dos demais tipos de deficiência. 
Além disso, Castro et al. (2017) e Becker (2019) evidenciaram a menor remuneração das pessoas com deficiência, que se deve tanto à discriminação como também às características produtivas desse grupo. Dessa forma, os autores argumentam que, além das políticas públicas que garantem a participação das pessoas com deficiência no mercado de trabalho, é necessário promover o treinamento e a qualificação necessários para que essas pessoas desenvolvam o seu pleno potencial produtivo.

\section{Método}

O propósito do estudo é estimar o efeito das deficiências sobre a probabilidade (relativa) de estudar e/ou trabalhar para os jovens de 15 a 24 anos, com base nas informações da Pesquisa Nacional de Saúde de 2013/Instituto Brasileiro de Geografia e Estatística (PNS/IBGE).

\subsection{Base de dados - PNS 2013}

A população de estudo da Pesquisa Nacional de Saúde - PNS 2013 compreendeu moradores de domicílios particulares do Brasil. A amostra baseou-se no Sistema Integrado de Pesquisas Domiciliares (SIPD) do IBGE, cuja abrangência geográfica é constituída pelos setores censitários da Base Operacional Geográfica do Censo Demográfico 2010, exceto aqueles com número muito pequeno de domicílios e os setores especiais. Dessa forma, as informações da PNS foram coletadas através de uma amostra probabilística de domicílios, com o objetivo de produzir dados sobre a situação de saúde da população brasileira, coletando também informações sobre educação, trabalho e rendimento, entre outras (IBGE, 2014).

$\mathrm{Na}$ amostra socioeconômica do Censo Demográfico de 2000 e 2010, também são coletadas essas informações, porém, para analisar questões relacionadas às pessoas com deficiência, a PNS seria mais indicada porque, para identificar essa condição, pergunta-se diretamente se a pessoa "tem deficiência", enquanto a pergunta do Censo Demográfico é se a pessoa "tem dificuldade permanente de enxergar/ouvir/caminhar". Então, é possível que os respondentes possam se confundir com a pergunta e declarar ter alguma dificuldade que não esteja, necessariamente, relacionada a uma 
deficiência. Além disso, no caso da deficiência física, a pergunta do Censo identifica apenas as pessoas que apresentam dificuldade de caminhar ou subir degraus e, portanto, não abrange, por exemplo, as pessoas que possuem comprometimento dos membros superiores. Por isso, optou-se por utilizar a base de dados da PNS para estimar o efeito das deficiências sobre a probabilidade (relativa) de estudar e/ou trabalhar para os jovens.

\subsection{Modelo}

Para estimar a probabilidade (relativa) de o jovem trabalhar e/ou estudar, considerando também aqueles que procuram mas não conseguem trabalho, utiliza-se um modelo logit multinomial com seis categorias exaustivas e mutuamente exclusivas:

a) Não estuda, não trabalha e não procura emprego (NE NT NP)

b) Não estuda, não trabalha e procura emprego (NE NT P)

c) Estuda, não trabalha e procura emprego (E NT P)

d) Estuda, não trabalha e não procura emprego (E NT NP)

e) Não estuda e trabalha (NE T)

f) Estuda e trabalha (E T)

$\mathrm{Na}$ PNS, define-se a pessoa que estuda como aquela que respondeu que frequenta a escola. Já a pessoa que trabalha é aquela que exerceu alguma atividade remunerada, durante pelo menos uma hora na semana de referência. A pessoa que procura emprego é aquela que tomou alguma providência para conseguir trabalho na semana de referência.

O resultado, $y_{i}$, do indivíduo $i$ é uma das seis categorias descritas anteriormente, indicadas por $h$. A probabilidade de o $i$-ésimo jovem pertencer à categoria $h$ é indicada por $p_{i h}$. Seja $x_{i}^{\prime}$ o vetor-linha com os valores das variáveis explanatórias para o $i$-ésimo jovem e $\beta_{h}$ os vetores-coluna de parâmetros para as $h$ categorias, o modelo de logit multinomial pode ser expresso pela seguinte equação:

$$
p_{i h}=\operatorname{Pr}\left(y_{i}=h\right)=\frac{\exp \left(x_{i}^{\prime} \beta_{h}\right)}{\sum_{j=1}^{4} \exp \left(x_{i}^{\prime} \beta_{j}\right)} \text { onde } 0<p_{i h}<1
$$

Assim, deseja-se analisar como a probabilidade $p_{i h}$ depende das características do jovem, entre as quais, a presença da deficiência. 


\subsection{Variáveis de interesse}

De maneira geral, a deficiência pode afetar a probabilidade de o jovem estudar/trabalhar/procurar emprego através de dois canais. $O$ primeiro ocorre quando a deficiência dificulta ou impede a execução de uma tarefa ou ação por um indivíduo, o que o modelo de "síntese biopsicossocial" denomina de limitações da atividade. Já o segundo pode estar relacionado à discriminação, uma vez que a participação econômica e social de uma pessoa com deficiência está relacionada com a maneira com a qual a sociedade lida com essa condição (OMS, 2013).

A estratégia para identificar como as limitações da atividade e a discriminação podem afetar a probabilidade de o jovem estudar/trabalhar/procurar emprego é semelhante à abordagem adotada por Jones et al. (2006). Nessa abordagem, as pessoas que não possuem deficiência compõem o grupo 1, e as pessoas com deficiência são distribuídas entre aquelas que não possuem limitações das atividades habituais (grupo 2) e aquelas que possuem tais limitações (grupo 3).

Supondo que os jovens cuja deficiência não traz limitações para as atividades habituais (grupo 2) têm a mesma capacidade de inserção no mercado de trabalho e nas atividades acadêmicas dos jovens que não possuem deficiência (grupo 1), uma possível menor probabilidade estimada de estudar/trabalhar/procurar emprego do grupo 2 em relação ao grupo 1 pode ser interpretada como uma estimativa de discriminação.

Partindo da hipótese de que o grau de discriminação contra pessoas com deficiência que possuem limitações das atividades habituais (grupo 3) é o mesmo ou maior que o grau de discriminação contra aquelas que não possuem limitações (grupo 2), a probabilidade estimada de estudar/ trabalhar/procurar emprego do grupo 3 em relação às pessoas que não possuem deficiência (grupo 1) deverá captar tanto essa possível discriminação como também as limitações geradas pela deficiência, que podem dificultar a inserção no mercado de trabalho e a realização das atividades educacionais.

A PNS permite que a pessoa classifique em que grau a deficiência limita as atividades habituais (como ir à escola, brincar, trabalhar etc.). Dessa forma, as quatro variáveis que identificam o tipo de deficiência, descritas a seguir, foram definidas como variáveis categóricas que diferenciam os jovens que não possuem deficiência (grupo 1 - categoria base), daqueles cuja 
deficiência não limita as atividades habituais (grupo 2) e também daquelas cuja deficiência limita tais atividades (grupo 3).

O tipo de deficiência pode afetar de diferentes formas a probabilidade de o jovem estudar/trabalhar/procurar emprego. Por exemplo, um jovem com deficiência intelectual pode ter mais dificuldade de realizar as atividades convencionais de estudo do que um jovem com deficiência física. Além disso, Jones et al. (2006) destaca ainda que as pessoas com deficiência intelectual podem ter maiores dificuldades de conseguir trabalho porque os empregadores estão mais familiarizados com os ajustes de infraestrutura demandados pelas pessoas com deficiência física do que com os ajustes nas rotinas de trabalho necessários para as pessoas com deficiência intelectual e, devido à falta de conhecimento, podem, equivocadamente, relacionar essa condição com uma menor habilidade para o trabalho.

Por isso, foram definidas quatro variáveis que identificam as pessoas com deficiência intelectual, deficiência física, deficiência auditiva e deficiência visual. A deficiência intelectual caracteriza-se pelo funcionamento cognitivo abaixo da média e pode estar associada a síndromes ou transtornos de desenvolvimento como a síndrome de Down, autismo, paralisia cerebral, acidente vascular cerebral, derrame, aneurisma, epilepsia ou demência senil. A deficiência física refere-se a alteração completa ou parcial de um ou mais segmentos do corpo, que podem ser decorrentes da amputação ou ausência do segmento, paralisia permanente, deformidade congênita, ostamia, nanismo, deficiência motora devido a poliomielite ou paralisia infantil. A deficiência auditiva refere-se a audição reduzida ou surdez de um ou ambos os ouvidos, e a deficiência visual refere-se a baixa visão ou cegueira de um ou de ambos os olhos.

\subsection{Variáveis de controle}

As variáveis de controle podem ser organizadas em três grupos. O primeiro refere-se às características do jovem e compreende as variáveis idade, cor e mulher. A variável cor é uma binária que assume valor 1 se a pessoa é indígena, preta ou parda, e 0 se a pessoa é branca ou amarela, já a variável mulher assume valor 1 para mulher e 0 para homem. Espera-se que, quanto maior a idade do jovem, maior a probabilidade de trabalhar e menor de estudar. As evidências da literatura apontam que mulheres e indivíduos não 
brancos tem menor probabilidade de trabalhar e estudar, em comparação aos homens e indivíduos brancos, respectivamente, o que pode ser devido à discriminação associada a esses grupos (Costa et al. 2013; Vieira et al. 2016).

Também foi incluída no modelo uma variável binária para identificar o jovem que é chefe de família, uma vez que essa condição pode interferir nas decisões de estudar/trabalhar/procurar emprego, e uma variável binária para identificar os jovens que recebiam aposentadoria ou pensão de instituto de previdência oficial (federal, estadual ou municipal). A introdução dessa variável no modelo justifica-se pelo fato de que aposentadorias e pensões são, em alguns casos, concedidas aos jovens com deficiência, principalmente para aqueles que possuem dificuldades severas, e podem estar associadas à probabilidade de o jovem estudar/trabalhar/ procurar emprego.

O segundo grupo de variáveis refere-se às características dos moradores do domicílio do jovem. A primeira delas é a renda domiciliar per capita (ln RDPC), pois, conforme Menezes-Filho et al. (2014), um aumento nessa variável permite uma alteração na alocação intrafamiliar de ren$\mathrm{da}$, de forma que os pais despendem mais recursos em investimento na educação de seus filhos. Vale destacar que foi excluído dessa variável o eventual rendimento de trabalho do jovem considerado na definição da variável dependente.

Além disso, alguns estudos da literatura apontam que fatores como o tamanho da família, o número de crianças e a escolaridade das pessoas do domicílio podem influenciar a alocação de jovens entre os estudos e o mercado de trabalho (Reis; Camargo, 2007; Hoffmann, 2010; Camarano; Kanso, 2012; Vieira et al. 2016). Assim, as demais variáveis do grupo de características do domicílio referem-se ao número de pessoas, número de menores de 10 anos e ao número de pessoas com ensino superior. Nessa última, exclui-se o eventual fato de jovem considerado na definição da variável dependente ter alcançado esse nível de instrução.

O último grupo de variáveis refere-se às características de localização do domicílio e é composto pelas variáveis rural e região. A primeira identifica os jovens que residem na área rural, pois, conforme Costa et al. (2013), muitos desses jovens não têm acesso à escola e desde muito cedo ajudam os pais no cultivo de lavouras ou nos afazeres domésticos. Já a região é uma variável categórica para as cinco regiões geográficas do país, onde a categoria base é a região Nordeste. 


\section{Estatísticas descritivas}

A amostra é composta por 33.159 observações dos jovens de 15 a 24 anos, observados da PNS de 2013. Dessa amostra, 96,6\% dos jovens não possuem deficiência, ${ }^{4} 0,7 \%$ possui deficiência intelectual, $0,6 \%$ possui deficiência física, $0,5 \%$ possui deficiência auditiva e $1,6 \%$ possuem deficiência visual.

$\mathrm{Na}$ Figura 1 é possível observar que muitos jovens cuja deficiência limita as atividades habituais, não estudam, não trabalham e não procuram emprego (NE NT NP). A exceção são os jovens com deficiência visual e limitações, para os quais a proporção dos que não estudam, não trabalham e não procuram emprego, $16 \%$, é semelhante à proporção de $17 \%$ dos jovens que não possuem deficiência, denominados, popularmente, como "nem-nem". Vale ressaltar que a distribuição de jovens com deficiência visual nas categorias estuda/trabalha/procura emprego é, de certa forma, semelhante à distribuição dos jovens que não possuem deficiência.

Para os jovens com deficiência intelectual e limitações das atividades habituais, a proporção daqueles que não estudam, não trabalham e não procuram emprego é $61 \%$. Já a maioria dos jovens que possuem essa deficiência mas não apresentam tais limitações, 62\%, estudam (E NT NP). Em ambos os casos, parece haver uma dificuldade de inserção no mercado de trabalho das pessoas com essa deficiência.

Conforme Jones et al. (2006), as razões para essa dificuldade são difíceis de determinar, mas dois fatores parecem ser importantes. O primeiro é que os empregadores podem, por diversas razões, ser mais relutantes em contratar pessoas com deficiência intelectual do que com outras formas de deficiência. Por exemplo, essa condição é, muitas vezes, equivocadamente relacionada com uma menor habilidade para o trabalho, de modo que as pessoas com deficiência intelectual tornam-se mais propensas a discriminação devido à falta de conhecimento. $O$ segundo fator é que os empregadores podem ter tendência a interpretar a deficiência física como mais "grave" e, portanto, concentrar-se nas adaptações de infraestrutura, em vez dos ajustes nas rotinas de trabalho que, geralmente, são demandados pelas pessoas com deficiência intelectual.

4 Dessa forma, $3,4 \%$ dos jovens da amostra possuem alguma deficiência, valor um pouco acima da média de 1 a $2 \%$ dos países em desenvolvimento, observada no estudo de Filmer (2008). Talvez isso ocorra porque algumas das bases utilizadas pelo autor não consideram todos os tipos de deficiência, por exemplo, as informações da Mongólia contemplam apenas pessoas com deficiência visual e auditiva, e do Burundi, apenas pessoas com deficiência física. 
Figura 1 Distribuição da amostra de jovens nas categorias variável dependente, condicionada à presença de deficiência

\section{Não deficiente}
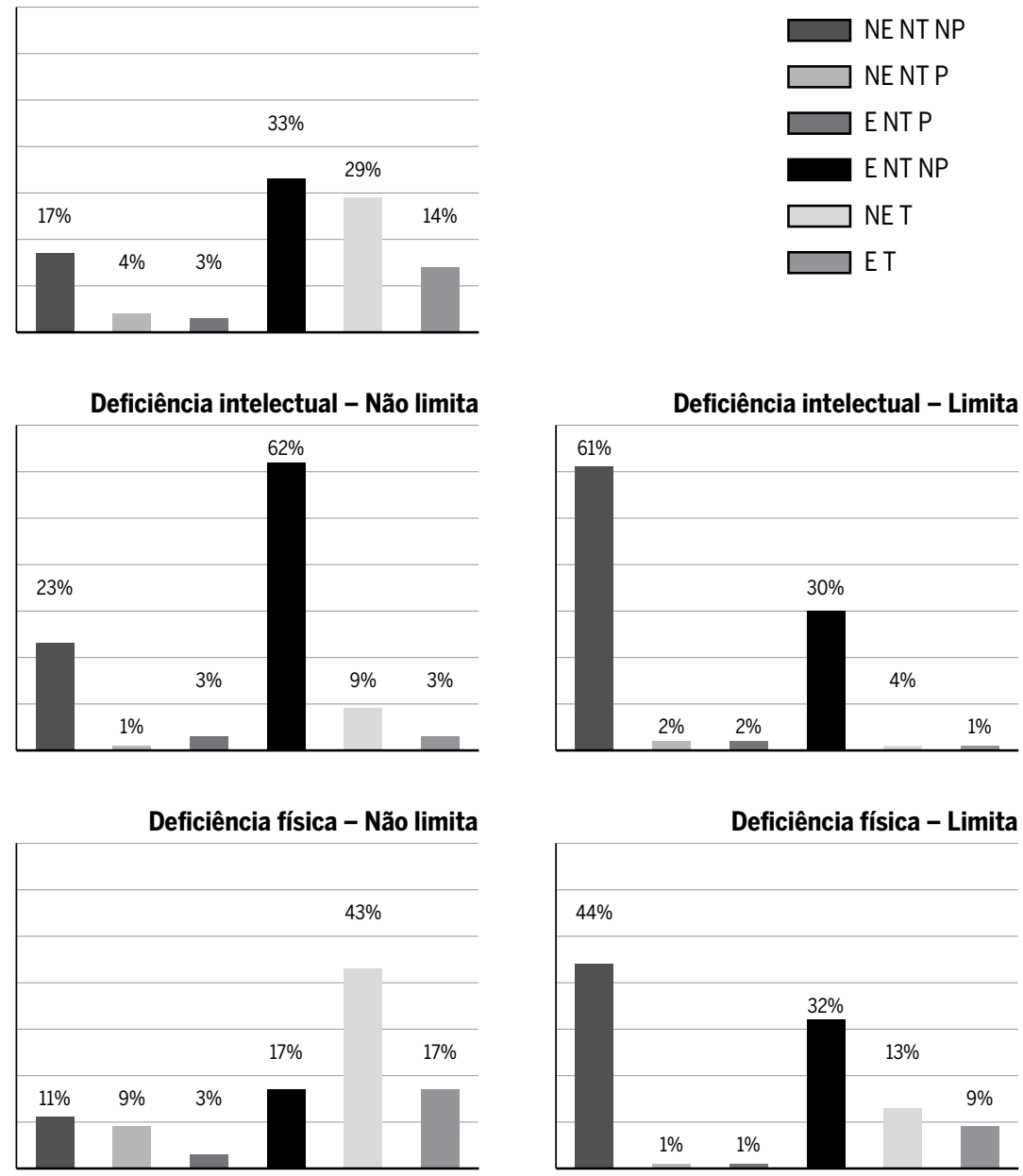

Deficiência auditiva - Não limita

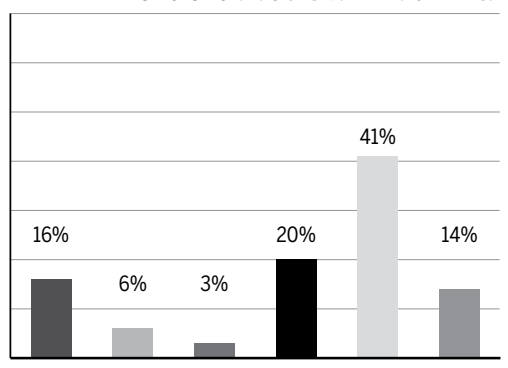

Deficiência auditiva - Limita

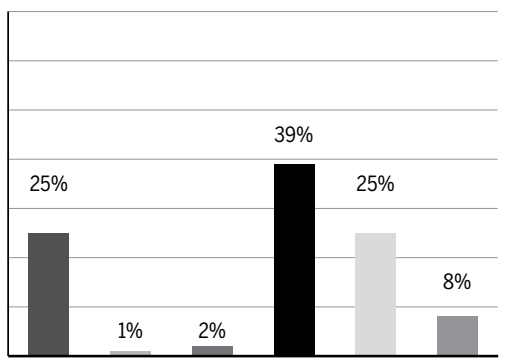


Figura 1 (continuação)
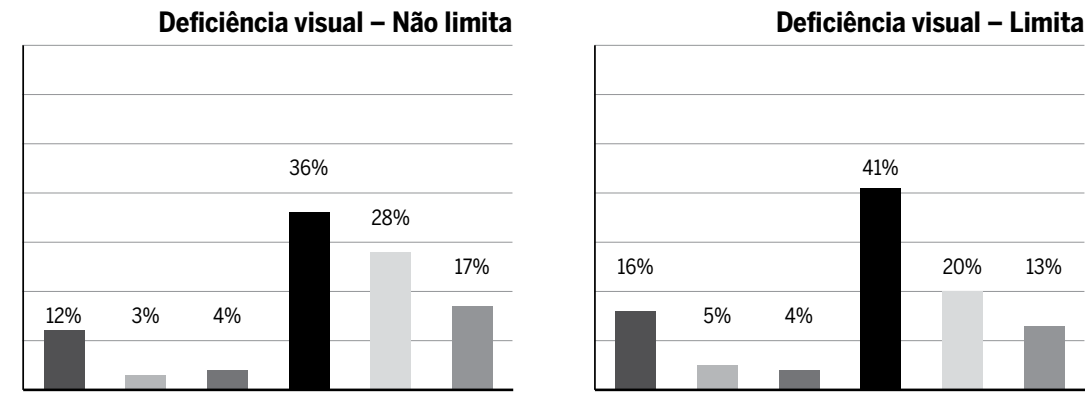

Fonte: PNS (2013).

Nota: Valores da amostra selecionada, ponderada pelo fator de expansão, conforme representado no Apêndice 1 do material suplementar, que pode ser obtido com a autora.

A declaração de que a deficiência limita ou não as atividades habituais pode ser, de certa forma, influenciada pelos efeitos composicionais. Dessa forma, a Tabela 1 apresenta as variáveis de controle do modelo, condicionada à presença de deficiência.

A média de idade dos jovens que compõem a amostra é entre 18 e 20 anos, e pouco mais da metade deles declaram-se negros, pardos ou indígenas. Em 2013, aproximadamente $51 \%$ da população brasileira era composta por mulheres. ${ }^{5}$ Porém, essa proporção é menor entre os jovens com deficiência na amostra da PNS, principalmente no caso daqueles declarados com deficiência sensorial ou física que não limita as atividades habituais. Através das informações coletadas por amostragem estratificada por conglomerados no estado de São Paulo em 2002 e 2003, Castro et al. (2008) também observaram maior prevalência das deficiências auditiva e física entre os homens.

Menos de $1 \%$ dos jovens com deficiência intelectual são chefes de família. Daqueles com deficiência física ou sensorial sem limitações das atividades, aproximadamente $4 \%$ são chefes, enquanto, para aqueles com limitações, os valores são $8 \%$ para deficiência física e 14\% para sensorial. Dos jovens com deficiência intelectual, $24 \%$ daqueles com limitações recebem aposentadoria ou pensão do governo, enquanto entre os que não possuem limitações, $11,5 \%$ recebem tal benefício. No caso dos jovens com deficiência física, os valores são $17 \%$ e $5,5 \%$, respectivamente. Já entre os 
jovens com deficiência sensorial, a proporção daqueles que recebem aposentadoria ou pensão é aproximadamente $9 \%$, tanto para os que possuem limitações como para os que não possuem.

Tabela 1 Média das variáveis de controle, condicionada à presença de deficiência

\begin{tabular}{|c|c|c|c|c|c|c|c|c|c|}
\hline & \multirow{2}{*}{ Não def. } & \multicolumn{2}{|c|}{ Def. intelectual } & \multicolumn{2}{|c|}{ Def. física } & \multicolumn{2}{|c|}{ Def. auditiva } & \multicolumn{2}{|c|}{ Def. visual } \\
\hline & & N.L. & L. & N.L. & L. & N.L. & L. & N. L. & L. \\
\hline Idade & $\begin{array}{r}19.324 \\
(0.001)\end{array}$ & $\begin{array}{l}18.866 \\
(0.014)\end{array}$ & $\begin{array}{r}19.367 \\
(0.006)\end{array}$ & $\begin{array}{l}19.250 \\
(0.014)\end{array}$ & $\begin{array}{r}18.780 \\
(0.007)\end{array}$ & $\begin{array}{r}20.734 \\
(0.009)\end{array}$ & $\begin{array}{r}18.939 \\
(0.006)\end{array}$ & $\begin{array}{r}20.734 \\
(0.009)\end{array}$ & $\begin{array}{r}19.325 \\
(0.009)\end{array}$ \\
\hline Idade & $\begin{array}{r}0.569 \\
(0.000)\end{array}$ & $\begin{array}{r}0.634 \\
(0.003)\end{array}$ & $\begin{array}{r}0.518 \\
(0.001)\end{array}$ & $\begin{array}{r}0.528 \\
(0.003)\end{array}$ & $\begin{array}{r}0.566 \\
(0.001)\end{array}$ & $\begin{array}{r}0.607 \\
(0.002)\end{array}$ & $\begin{array}{r}0.574 \\
(0.001)\end{array}$ & $\begin{array}{r}0.607 \\
(0.002)\end{array}$ & $\begin{array}{r}0.573 \\
(0.002)\end{array}$ \\
\hline Mulher & $\begin{array}{r}0.511 \\
(0.000)\end{array}$ & $\begin{array}{r}0.488 \\
(0.003)\end{array}$ & $\begin{array}{r}0.416 \\
(0.001)\end{array}$ & $\begin{array}{r}0.250 \\
(0.002)\end{array}$ & $\begin{array}{r}0.418 \\
(0.001)\end{array}$ & $\begin{array}{r}0.386 \\
(0.002)\end{array}$ & $\begin{array}{r}0.487 \\
(0.001)\end{array}$ & $\begin{array}{r}0.386 \\
(0.002)\end{array}$ & $\begin{array}{r}0.423 \\
(0.002)\end{array}$ \\
\hline Chefe & $\begin{array}{r}0.070 \\
(0.000)\end{array}$ & $\begin{array}{r}0.001 \\
(0.000)\end{array}$ & $\begin{array}{r}0.003 \\
(0.000)\end{array}$ & $\begin{array}{r}0.083 \\
(0.002)\end{array}$ & $\begin{array}{r}0.043 \\
(0.001)\end{array}$ & $\begin{array}{r}0.147 \\
(0.001)\end{array}$ & $\begin{array}{r}0.042 \\
(0.000)\end{array}$ & $\begin{array}{r}0.147 \\
(0.001)\end{array}$ & $\begin{array}{r}0.035 \\
(0.001)\end{array}$ \\
\hline Aposentadoria & $\begin{array}{r}0.006 \\
(0.000)\end{array}$ & $\begin{array}{r}0.115 \\
(0.002)\end{array}$ & $\begin{array}{r}0.239 \\
(0.001)\end{array}$ & $\begin{array}{r}0.055 \\
(0.001)\end{array}$ & $\begin{array}{r}0.171 \\
(0.001)\end{array}$ & $\begin{array}{r}0.091 \\
(0.001)\end{array}$ & $\begin{array}{r}0.093 \\
(0.000)\end{array}$ & $\begin{array}{r}0.091 \\
(0.001)\end{array}$ & $\begin{array}{r}0.094 \\
(0.001)\end{array}$ \\
\hline $\ln (\mathrm{RDPC})$ & $\begin{array}{r}6.114 \\
(0.000)\end{array}$ & $\begin{array}{r}5.920 \\
(0.006)\end{array}$ & $\begin{array}{r}6.133 \\
(0.002)\end{array}$ & $\begin{array}{r}6.113 \\
(0.005)\end{array}$ & $\begin{array}{r}6.173 \\
(0.002)\end{array}$ & $\begin{array}{r}5.735 \\
(0.004)\end{array}$ & $\begin{array}{r}5.969 \\
(0.002)\end{array}$ & $\begin{array}{r}5.735 \\
(0.004)\end{array}$ & $\begin{array}{r}6.011 \\
(0.003)\end{array}$ \\
\hline N. pes & $\begin{array}{r}4.297 \\
(0.000)\end{array}$ & $\begin{array}{r}4.573 \\
(0.007)\end{array}$ & $\begin{array}{r}4.338 \\
(0.003)\end{array}$ & $\begin{array}{r}4.047 \\
(0.011)\end{array}$ & $\begin{array}{r}4.330 \\
(0.004)\end{array}$ & $\begin{array}{r}4.280 \\
(0.005)\end{array}$ & $\begin{array}{r}4.595 \\
(0.004)\end{array}$ & $\begin{array}{r}4.280 \\
(0.005)\end{array}$ & $\begin{array}{r}4.358 \\
(0.006)\end{array}$ \\
\hline N. mer & $\begin{array}{r}0.458 \\
(0.000)\end{array}$ & $\begin{array}{r}0.134 \\
(0.002)\end{array}$ & $\begin{array}{r}0.328 \\
(0.001)\end{array}$ & $\begin{array}{r}0.556 \\
(0.005)\end{array}$ & $\begin{array}{r}0.344 \\
(0.002)\end{array}$ & $\begin{array}{r}0.677 \\
(0.003)\end{array}$ & $\begin{array}{r}0.471 \\
(0.002)\end{array}$ & $\begin{array}{r}0.677 \\
(0.003)\end{array}$ & $\begin{array}{r}0.382 \\
(0.002)\end{array}$ \\
\hline N. Ens. superior & $\begin{array}{r}0.206 \\
(0.000)\end{array}$ & $\begin{array}{r}0.138 \\
(0.003)\end{array}$ & $\begin{array}{r}0.177 \\
(0.001)\end{array}$ & $\begin{array}{r}0.111 \\
(0.001)\end{array}$ & $\begin{array}{r}0.165 \\
(0.001)\end{array}$ & $\begin{array}{r}0.212 \\
(0.002)\end{array}$ & $\begin{array}{r}0.150 \\
(0.001)\end{array}$ & $\begin{array}{r}0.212 \\
(0.002)\end{array}$ & $\begin{array}{r}0.183 \\
(0.001)\end{array}$ \\
\hline Rural & $\begin{array}{r}0.143 \\
(0.000)\end{array}$ & $\begin{array}{r}0.243 \\
(0.003)\end{array}$ & $\begin{array}{r}0.150 \\
(0.001)\end{array}$ & $\begin{array}{r}0.111 \\
(0.002)\end{array}$ & $\begin{array}{r}0.151 \\
(0.001)\end{array}$ & $\begin{array}{r}0.167 \\
(0.001)\end{array}$ & $\begin{array}{r}0.226 \\
(0.001)\end{array}$ & $\begin{array}{r}0.167 \\
(0.001)\end{array}$ & $\begin{array}{r}0.223 \\
(0.001)\end{array}$ \\
\hline Norte & $\begin{array}{r}0.092 \\
(0.000)\end{array}$ & $\begin{array}{r}0.129 \\
(0.002)\end{array}$ & $\begin{array}{r}0.111 \\
(0.001)\end{array}$ & $\begin{array}{r}0.049 \\
(0.001)\end{array}$ & $\begin{array}{r}0.128 \\
(0.001)\end{array}$ & $\begin{array}{r}0.062 \\
(0.001)\end{array}$ & $\begin{array}{r}0.138 \\
(0.001)\end{array}$ & $\begin{array}{r}0.062 \\
(0.001)\end{array}$ & $\begin{array}{r}0.047 \\
(0.001)\end{array}$ \\
\hline Sudeste & $\begin{array}{r}0.402 \\
(0.000)\end{array}$ & $\begin{array}{r}0.285 \\
(0.002)\end{array}$ & $\begin{array}{r}0.470 \\
(0.001)\end{array}$ & $\begin{array}{r}0.276 \\
(0.003)\end{array}$ & $\begin{array}{r}0.356 \\
(0.001)\end{array}$ & $\begin{array}{r}0.395 \\
(0.002)\end{array}$ & $\begin{array}{r}0.311 \\
(0.001)\end{array}$ & $\begin{array}{r}0.395 \\
(0.002)\end{array}$ & $\begin{array}{r}0.396 \\
(0.002)\end{array}$ \\
\hline Sul & $\begin{array}{r}0.134 \\
(0.000)\end{array}$ & $\begin{array}{r}0.141 \\
(0.002)\end{array}$ & $\begin{array}{r}0.114 \\
(0.001)\end{array}$ & $\begin{array}{r}0.079 \\
(0.002)\end{array}$ & $\begin{array}{r}0.085 \\
(0.001)\end{array}$ & $\begin{array}{r}0.186 \\
(0.001)\end{array}$ & $\begin{array}{r}0.168 \\
(0.001)\end{array}$ & $\begin{array}{r}0.186 \\
(0.001)\end{array}$ & $\begin{array}{r}0.110 \\
(0.001)\end{array}$ \\
\hline Centro-0este & $\begin{array}{r}0.077 \\
(0.000)\end{array}$ & $\begin{array}{r}0.148 \\
(0.002)\end{array}$ & $\begin{array}{r}0.051 \\
(0.000)\end{array}$ & $\begin{array}{r}0.017 \\
(0.001)\end{array}$ & $\begin{array}{r}0.092 \\
(0.001)\end{array}$ & $\begin{array}{r}0.045 \\
(0.001)\end{array}$ & $\begin{array}{r}0.089 \\
(0.001)\end{array}$ & $\begin{array}{r}0.045 \\
(0.001)\end{array}$ & $\begin{array}{r}0.109 \\
(0.001)\end{array}$ \\
\hline Obs. & 30.316 .243 & 28.277 & 250.066 & 29.153 & 146.142 & 85.051 & 95.352 & 331.414 & 235.355 \\
\hline
\end{tabular}

Fonte: PNS (2013).

Nota: Valores da amostra selecionada para as estimações, ponderada pelo fator de expansão. Erro-padrão entre parênteses. N. L. significa não limita, e L. limita. 
A média da renda domiciliar per capita é semelhante entre os grupos, e os domicílios são compostos por quatro pessoas. Na maioria dos domicílios dos jovens de 15 a 24 anos não há crianças com menos de 10 anos (64\%) ou adultos com ensino superior (85\%), de modo que as médias dessas variáveis foram menores do que 1 para os grupos. A maioria dos jovens da amostra vivem na área urbana e na região Sudeste ou Nordeste, dependendo da categoria.

\section{Resultados}

A Tabela 2 apresenta as odds ratios obtidas a partir dos coeficientes estimados do modelo logit multinomial ${ }^{6}$ de probabilidade de estudar/trabalhar/procurar emprego dos jovens de 15 a 24 anos, observados da PNS de 2013. Com relação às variáveis de controle, de maneira geral, os resultados estão de acordo com o esperado e com as evidências da literatura abordada na seção 3.4.

As odds ratios da variável categórica que identifica pessoas com deficiência intelectual, obtidas a partir de coeficientes significativos, são menores do que 1 , indicando que as pessoas que possuem tal deficiência têm menores chances de trabalhar, estudar ou estar procurando emprego. No caso da educação, esse resultado pode decorrer do fato de que a deficiência intelectual, geralmente, caracteriza-se pelo funcionamento cognitivo abaixo da média e, se as rotinas educacionais não forem adaptadas, pode-se desestimular a frequência escolar e o aprendizado das pessoas com esse tipo de deficiência.

Já no caso do mercado de trabalho, as pessoas com deficiência intelectual, tanto aquelas com limitações das atividades habituais quanto aquelas que não possuem tais limitações, têm entre 0,02 e 0,03 vezes menor chance de trabalhar e estudar ou apenas trabalhar, em relação a não trabalhar, não estudar e não procurar emprego (categoria base), do que uma pessoa que não possui deficiência intelectual. Partindo da hipótese de que as pessoas cuja deficiência não limita as atividades habituais teriam a mesma capacidade de inserção no mercado de trabalho das pessoas sem deficiência, o resultado descrito acima pode ser um indicativo de que os empregadores discriminam as pessoas com deficiência intelectual, pois, conforme Jones

6 Os coeficientes estimados estão no Apêndice 2 do material suplementar. 
(2006), essa condição é, muitas vezes, equivocadamente relacionada com uma menor habilidade para o trabalho.

Tabela 2 Odds ratio das variáveis do modelo de probabilidade (relativa) de estudar/ trabalhar/procurar emprego para os jovens de 15 a 24 anos com deficiência

\begin{tabular}{|c|c|c|c|c|c|}
\hline Varlh. & NE NT P & E NT P & E NT NP & NET & ET \\
\hline \multicolumn{6}{|l|}{ Def. intelectual } \\
\hline Não limita & 0,0 & $0,497^{* * *}$ & $0,613^{* * *}$ & $0,022^{* * *}$ & $0,028^{* * *}$ \\
\hline Limita & $0,044^{* * *}$ & $0,064^{* * *}$ & $0,176^{* * *}$ & $0,017^{* * *}$ & $0,028^{* * *}$ \\
\hline \multicolumn{6}{|l|}{ Def. física } \\
\hline Não limita & $8,566^{* * *}$ & $11,694^{* * *}$ & $3,587 * * *$ & $6,644^{* * *}$ & $13,578^{* * *}$ \\
\hline Limita & $0,157^{* * *}$ & $0,008^{* * *}$ & $0,346^{* * *}$ & $0,194^{* * *}$ & $0,342^{* * *}$ \\
\hline \multicolumn{6}{|l|}{ Def. auditiva } \\
\hline Não limita & $1,247^{* * *}$ & $0,208^{* * *}$ & $0,428^{* * *}$ & $0,566^{* * *}$ & $0,396^{* * *}$ \\
\hline Limita & $0,055^{* * *}$ & $0,566^{* * *}$ & $1,656^{* * *}$ & $0,256^{* * *}$ & $0,379 * * *$ \\
\hline \multicolumn{6}{|l|}{ Def. visual } \\
\hline Não limita & $1,084^{* * *}$ & $1,65^{* * *}$ & $1,394^{* * *}$ & $1,327^{* * *}$ & $1,587^{* * *}$ \\
\hline Limita & $1,086^{* * *}$ & $1,492^{* * *}$ & $1,756^{* * *}$ & $1,346^{* * *}$ & $1,679 * * *$ \\
\hline Idade & $1,109 * * *$ & $0,731^{* * *}$ & $0,565^{* * *}$ & $1,212^{* * *}$ & $0,911^{* * *}$ \\
\hline Cor & $1,054^{* * *}$ & $0,72^{* * *}$ & $0,752^{* * *}$ & $0,845^{* * *}$ & $0,826^{* * *}$ \\
\hline Mulher & $0,598^{* * *}$ & $0,618^{* * *}$ & $0,681^{* * *}$ & $0,314^{* * *}$ & $0,486^{* * *}$ \\
\hline Chefe & $0,948 * * *$ & $1,146^{* * *}$ & $0,67^{* * *}$ & $1,355^{* * *}$ & $0,872^{* * *}$ \\
\hline Aposentadoria & $0,736^{* * *}$ & $1,259 * * *$ & $0,703^{* * *}$ & $0,263^{* * *}$ & $0,298^{* * *}$ \\
\hline $\ln (\mathrm{RDPC})$ & $0,834^{* * *}$ & $1,273^{* * *}$ & $1,565^{* * *}$ & $1,076 * * *$ & $1,458^{* * *}$ \\
\hline N. pessoas & $1,148^{* * *}$ & $1,089 * * *$ & $1,076^{* * *}$ & $1,051^{* * *}$ & $1,07^{* * *}$ \\
\hline N. menor 10 & $0,632^{* * *}$ & $0,607^{* * *}$ & $0,61^{* * *}$ & $0,704^{* * *}$ & $0,59^{* * *}$ \\
\hline N. Ens. superior & $0,83^{* * *}$ & $1,112^{* * *}$ & $1,624^{* * *}$ & $0,639 * * *$ & $1,088^{* * *}$ \\
\hline Rural & $0,354^{* * *}$ & $0,262^{* * *}$ & $0,812^{* * *}$ & $0,622^{* * *}$ & $0,473^{* * *}$ \\
\hline \multicolumn{6}{|l|}{ Região } \\
\hline Norte & $0,596 * * *$ & $0,768^{* * *}$ & $0,913^{* * *}$ & $0,826^{* * *}$ & $1,014^{* * *}$ \\
\hline Sudeste & $1,24 * * *$ & $0,902^{* * *}$ & $0,634^{* * *}$ & $1,554^{* * *}$ & $1,091^{* * *}$ \\
\hline Sul & $1,428^{* * *}$ & $0,793^{* * *}$ & $0,502^{* * *}$ & $1,8^{* * *}$ & $1,635^{* * *}$ \\
\hline Centro-Oeste & $0,812^{* * *}$ & $0,861^{* * *}$ & $0,637^{* * *}$ & $1,514^{* * *}$ & $1,453^{* * *}$ \\
\hline Observações & 31.517 .053 & & & & \\
\hline Pseudo R2 & 0,185 & & & & \\
\hline$x^{2}(p$-valor $)$ & 0,00 & & & & \\
\hline
\end{tabular}

Fonte: PNS (2013). 
Notas: Coeficientes estimados no Apêndice 2 do material suplementar, que pode ser obtido com a autora, calculados a partir de uma amostra ponderada pelo fator de expansão.

Significância dos coeficientes: ${ }^{* *} 1 \%$; $*{ }^{*} 5 \%$; ${ }^{*} 10 \%$.

Já as pessoas com deficiência física que não possuem limitação às atividades habituais têm, aproximadamente, 7 vezes maior chance de trabalhar e 14 vezes maior chance de trabalhar e estudar, em relação à categoria base, do que uma pessoa que não possui tal deficiência. Esse resultado também está de acordo com Jones et al. (2006), segundo o qual os empregadores estão mais habituados às adaptações de infraestrutura demandadas pelas pessoas com deficiência física. Soma-se a isso o fato de que o empregador pode considerar mais apropriado contratar uma pessoa com deficiência física sem limitações das atividades habituais e, assim, cumprir as determinações da política de cotas de contratação de pessoas com deficiência, sem que sejam necessários ajustes significativos nas rotinas de trabalho.

Por outro lado, as pessoas com deficiência física com limitações às atividades habituais têm 0,19 vezes menor chance de trabalhar, em relação à categoria base, do que uma pessoa que não possui essa deficiência. Esse resultado pode estar associado às limitações causadas pela deficiência que, possivelmente, prejudicam a produtividade e, assim, a capacidade de inserção no mercado de trabalho ou, ainda, do fato de o empregador e o local de trabalho não fornecerem as condições e adaptações necessárias para que a pessoa possa exercer suas atividades e, de certa forma, discriminarem essa categoria.

As pessoas com limitações às atividades habituais também apresentam 0,35 vezes menor chance de estudar, em relação à categoria base, do que uma pessoa que não possui deficiência física. Esse resultado pode estar relacionado às dificuldades e limitações geradas pela deficiência ou ser um indicativo de que as políticas de educação especial e inclusiva não estão conseguindo alcançar essa população. Da mesma forma, as odds ratios de 0,16 e 0,01 que indicam, respectivamente, a menor chance de procurar emprego (NE NT P) e de estudar e procurar emprego (E NT P) podem estar associadas à severidade da deficiência ou ao desestímulo e dificuldade para enfrentar todas as barreiras que impedem o desenvolvimento das atividades educacionais e a participação no mercado de trabalho das pessoas com deficiência física com limitações das atividades. 
Já as pessoas com deficiência auditiva apresentam menores chances de trabalhar e estudar ou apenas trabalhar, em relação a não trabalhar, não estudar e não procurar emprego (categoria base), do que uma pessoa que não possui essa deficiência. Esse resultado também é observado para as pessoas que declararam que a deficiência auditiva não limita as atividades habituais, o que é uma evidência de que os empregadores também discriminam as pessoas dessa categoria de deficiência, assim como ocorre com as pessoas que possuem deficiência intelectual.

Por outro lado, as pessoas com deficiência auditiva com limitações às atividades habituais apresentam, aproximadamente, 1,6 vezes mais chance de estudar, em relação à categoria base, do que uma pessoa que não possui essa deficiência, enquanto aqueles que não possuem limitações apresentam 0,4 vezes menor chance de estudar. ${ }^{7}$ Esse resultado pode causar estranheza se partirmos da hipótese de que os jovens cuja deficiência auditiva causa limitações às atividades habituais enfrentariam maiores barreiras do que aqueles não possuem limitações.

Uma possível explicação para esse resultado é que, dada a dificuldade de inserção no mercado de trabalho dos jovens com deficiência auditiva e limitações das atividades, esses jovens estariam mais propensos a alocar o tempo na educação. Uma outra explicação, no campo das especulações, é que os jovens com limitações seriam direcionados para as escolas de educação bilíngue para surdos ou escolas regulares onde existem serviços especializados para atender as necessidades desses alunos. Já os jovens com deficiência auditiva que não possuem limitações seriam direcionados para escolas regulares com educação inclusiva, onde, muitas vezes, não existem recursos e profissionais especializados para atender as necessidades do aluno, o que acaba desestimulando a frequência escolar. Alguns autores de estudos na área da educação apontam para a falta de recursos especializados para promover a educação inclusiva, o que acaba dificultando a educação dessas crianças (Mendes, 2010; Meletti e Ribeiro, 2014).

Devido à política nacional de educação inclusiva, descrita na seção 2.2 , a grande maioria dos alunos que são público-alvo da educação especial estão matriculados em escolas regulares (Brasil, 2016). Conforme as informações do Censo Escolar da Educação Básica de 2016, dos alunos surdos matricu-

7 A subseção 5.1, a seguir, apresenta os resultados dos modelos estimados separadamente para mulheres e homens, e a maior probabilidade de estudar das pessoas com deficiência auditiva e limitações às atividades é observada apenas entre os homens. 
lados nessas escolas, 41,6\% recebem Atendimento Educacional Especializado (AEE), ${ }^{8}$ enquanto do total de alunos com deficiência auditiva $37,2 \%$ recebem esse atendimento. A proporção de alunos surdos em escolas ou turmas especiais é $14 \%$ maior do que os alunos com deficiência auditiva. ${ }^{9}$

Cabe ressaltar que a ideia apresentada nos parágrafos anteriores não é uma constatação de que a escola especializada seria melhor do que a escola inclusiva em termos de aprendizado e frequência escolar. pois, como não é o objeto deste estudo, não há elementos na análise que sustentem tal conclusão. A ideia é apenas aventar uma possível explicação para o resultado encontrado de frequência escolar de jovens com limitações às atividades, supondo que esses jovens, em maioria, frequentam escolas bilíngues ou com recursos especializadas e que os jovens com deficiência auditiva sem limitações às atividades frequentam a educação regular em escolas que, muitas vezes, conforme os pesquisadores na área da educação, ainda não possuem a infraestrutura prevista para atender as necessidades dos alunos.

Os resultados das odds ratios da variável categórica que identifica pessoas com deficiência visual indicaram que essas pessoas têm maiores chances de estudar/trabalhar/procurar emprego em relação à categoria base, do que pessoas que não possuem essa deficiência. Esse resultado pode ser um indicativo de que as políticas de qualificação profissional para pessoas com deficiência visual, como as que são desenvolvidas pelo Instituto Benjamin Constant, a política de cotas de emprego para pessoas com deficiência e as políticas de educação especial e inclusiva conseguem, de certa forma, alcançar essa população e produzir resultados em termos de incentivo à frequência escolar e à empregabilidade.

A odds ratio das pessoas com limitações às atividades habituais que apenas estudam foi 1,76 , enquanto para aquelas que não possuem tais limitações foi 1,40. Uma possível explicação pode ser a existência de escolas e serviços especializados na educação de cegos ou pessoas com comprometimento severo da visão que estimulam a frequência escolar dessa po-

8 O AEE é um conjunto de atividades, recursos pedagógicos e de acessibilidade, oferecidos de forma complementar ou suplementar à escolarização dos estudantes com necessidades especiais matriculados nas classes comuns do ensino regular (Brasil 2011; Brasil, 2015b).

9 No Censo Escolar, considera-se pessoa surda aquela que, por ter perda auditiva, compreende e interage com o mundo por meio de experiências visuais, manifestando sua cultura principalmente pelo uso da Língua Brasileira de Sinais - Libras. Considera-se deficiência auditiva a perda bilateral, parcial ou total, de quarenta e um decibéis (dB) ou mais. (Decreto $n^{\circ} 5.626$, de 22 de dezembro de 2005). Na PNS, a categoria de deficiência auditiva integra também pessoas consideradas surdas. 
pulação, assim como ocorre com os jovens com deficiência auditiva com limitações da atividade, enquanto aquelas pessoas que não possuem tais limitações podem não estar, necessariamente, recebendo o atendimento específico às suas necessidades. Conforme as informações do Censo Escolar de 2016, dos alunos com cegueira matriculados em escolas regulares, $50,4 \%$ recebem o AEE, enquanto do total de alunos com baixa visão apenas $29,8 \%$ recebem esse atendimento. A proporção de alunos com cegueira em escolas ou turmas especiais é $59 \%$ maior do que os alunos com baixa visão.

Vale destacar, novamente, que esse argumento é apenas uma tentativa de explicar as maiores chances de estudar das pessoas com deficiência sensorial, visual e auditiva, com limitações das atividades habituais, baseado nos estudos na área da educação que apontam a falta de recursos especializados para promover a educação inclusiva (Mendes, 2010; Meletti e Ribeiro, 2014).

\subsection{Resultados da análise para homens e mulheres}

Embora as mulheres representassem 51\% na população brasileira em 2013, entre os jovens com deficiência na amostra da PNS, essa proporção é menor, principalmente no caso da deficiência física que não limita as atividades habituais, no qual as mulheres representaram $25 \%$ do total de jovens nesse grupo, conforme a Tabela 1. Evidências da literatura apontam que as mulheres jovens apresentam menores chances de estudar e/ou trabalhar em relação aos homens, o que pode estar relacionado a fatores como discriminação, cultura ou maternidade (Costa et al. 2013; Vieira et al. 2016).

Dessa forma, é possível que os diferenciais nos resultados das categorias de deficiência e nos grupos que declararam limitação ou não possam estar influenciados pelos efeitos composicionais de gênero, dada a diferença na proporção de mulheres entre grupos analisados. Diante disso, a Tabela 3 apresenta os resultados do modelo estimado separadamente para mulheres e homens, a fim de observar se existem diferenças no efeito das deficiências e suas limitações sobre a probabilidade de procurar emprego, trabalhar e/ou estudar.

No caso da deficiência intelectual e física, as direções das odds ratios para homens e mulheres foram semelhantes àquelas observadas na Tabela 2 , ou seja, pessoas com deficiência intelectual têm menores chances de 
procurar emprego, trabalhar e estudar, do que aqueles que não possuem essa deficiência, assim como as pessoas com deficiência física que limita as atividades. Já aquelas com deficiência física sem limitações apresentam maiores chances.

As principais diferenças observadas entre homens e mulheres são entre aqueles que possuem deficiência sensorial. As mulheres cuja deficiência auditiva não limita as atividades apresentam maiores chances de procurar emprego (NE NT P), de estudar e trabalhar (E T) e de apenas trabalhar (NE T), em relação a não trabalhar, não estudar e não procurar emprego (categoria base), do que uma mulher que não possui tais deficiências, enquanto os homens têm menores chances, em relação aos homens na categoria base.

Isso pode ser uma evidência de que, talvez, as políticas de inclusão no mercado de trabalho para pessoas com deficiência auditiva atingem, principalmente, as mulheres sem limitações das atividades, uma vez que essas mulheres estão em busca de inserção e, de certa forma, conseguem encontrar oportunidades.

Vale destacar ainda que, assim como ocorre com as pessoas com deficiência física sem limitações, talvez, para cumprir as determinações da política de cotas de contratação de pessoas com deficiência, o empregador considere mais apropriado contratar uma pessoa sem limitações e, no caso da deficiência sensorial, isso possa ser observado entre as mulheres. Porém, isso, talvez, tenha reflexos no tempo alocado para os estudos, uma vez que a odds ratio associada à chance de uma mulher com deficiência auditiva apenas estudar é menor do que 1.

$\mathrm{Na}$ seção anterior, observou-se que as pessoas com deficiência auditiva com limitações das atividades habituais possuem maior chance de estudar, em relação à categoria base, do que uma pessoa que não possui essa deficiência (Tabela 2). Na Tabela 3, esse resultado é observado apenas para os homens, uma vez que as mulheres apresentam 0,71 vezes menores chances de apenas estudar (E NT NP), em relação às mulheres que não possuem deficiência auditiva com limitações das atividades. Dessa forma, as possíveis explicações para esse resultado discutidas anteriormente, de que os jovens com dificuldades severas de audição teriam maior incentivo para estudar por serem direcionados para escolas com serviços especializados ou que, dada a dificuldade de inserção no mercado de trabalho, esses jovens estariam mais propensos a alocar o tempo na educação, parecem ser válidas apenas para os jovens do sexo masculino. 
Tabela 3 Odds ratio das variáveis do modelo de probabilidade (relativa) de estudar/ trabalhar/procurar emprego para jovens de 15 a 24 anos, por sexo

\begin{tabular}{|c|c|c|c|c|c|}
\hline $\begin{array}{l}\text { Varlh. } \\
\text { Mulheres }\end{array}$ & NE NT P & E NT P & E NT NP & NE T & E T \\
\hline \multicolumn{6}{|c|}{ Def. intelectual } \\
\hline Não limita & $0,01^{* * *}$ & $0,409 * * *$ & $0,25^{* * *}$ & $0,003^{* * *}$ & $0,008^{* * *}$ \\
\hline Limita & $0,067^{* * *}$ & $0,093^{* * *}$ & $0,319 * * *$ & $0,015^{* * *}$ & $0,035^{* * *}$ \\
\hline \multicolumn{6}{|l|}{ Def. física } \\
\hline Não limita & 0,0 & $7,709 * * *$ & $2,858^{* * *}$ & $9,649 * * *$ & $4,314^{* * *}$ \\
\hline Limita & $0,09 * * *$ & $0,039^{* * *}$ & $0,454^{* * *}$ & $0,199 * * *$ & $0,229 * * *$ \\
\hline \multicolumn{6}{|c|}{ Def. auditiva } \\
\hline Não limita & $2,313^{* * *}$ & $0,017^{* * *}$ & $0,556^{* * *}$ & $1,201^{* * *}$ & $1,193^{* * *}$ \\
\hline Limita & $0,195^{* * *}$ & $0,113^{* * *}$ & $0,709 * * *$ & $0,533^{* * *}$ & $0,401^{* * *}$ \\
\hline \multicolumn{6}{|l|}{ Def. visual } \\
\hline Não limita & $1,419 * * *$ & $1,43^{* * *}$ & $1,692^{* * *}$ & $1,735^{* * *}$ & $2,625^{* * *}$ \\
\hline Limita & $1,498^{* * *}$ & $2,321^{* * *}$ & $1,341^{* * *}$ & $1,088^{* * *}$ & $2,126^{* * *}$ \\
\hline $\begin{array}{l}\text { Varih. } \\
\text { Homens }\end{array}$ & NE NT P & E NT P & E NT NP & NE T & $\mathbf{E T}$ \\
\hline \multicolumn{6}{|c|}{ Def. intelectual } \\
\hline Não limita & 0,0 & 0,0 & $0,158^{* * *}$ & $0,078^{* * *}$ & $0,263^{* * *}$ \\
\hline Limita & $0,038^{* * *}$ & $0,06^{* * *}$ & $0,162^{* * *}$ & $0,025^{* * *}$ & $0,027^{* * *}$ \\
\hline \multicolumn{6}{|l|}{ Def. física } \\
\hline Não limita & $5,29 * * *$ & 0,0 & $2,904^{* * *}$ & $3,28^{* * *}$ & $8,601^{* * *}$ \\
\hline Limita & $0,23^{* * *}$ & $0,015^{* * *}$ & $0,316^{* * *}$ & $0,214^{* * *}$ & $0,425^{* * *}$ \\
\hline \multicolumn{6}{|c|}{ Def. auditiva } \\
\hline Não limita & $0,293^{* * *}$ & $0,224^{* * *}$ & $0,191^{* * *}$ & $0,341^{* * *}$ & $0,14^{* * *}$ \\
\hline Limita & $0^{* * *}$ & 0,996 & $2,765^{* * *}$ & $0,217^{* * *}$ & $0,447^{* * *}$ \\
\hline \multicolumn{6}{|l|}{ Def. visual } \\
\hline Não limita & $0,758^{* * *}$ & $1,442^{* * *}$ & $1,049 * * *$ & $1,081^{* * *}$ & $1,295^{* * *}$ \\
\hline Limita & $0,79 * * *$ & $0,485^{* * *}$ & $2,81^{* * *}$ & $1,784^{* * *}$ & $1,518^{* * *}$ \\
\hline
\end{tabular}

Fonte: PNS (2013).

Notas: Coeficientes estimados nos Apêndices 3 e 4 do material suplementar, que pode ser obtido com a autora, a partir de uma amostra ponderada pelo fator de expansão.

Significância dos coeficientes: ${ }^{* *} 1 \%$; **5\%; * $10 \%$. 
Esse resultado reforça o argumento dos educadores especiais de que ainda são necessários maiores investimentos para promover a educação de pessoas com deficiência, uma vez que os resultados positivos são observados apenas para alguns subgrupos de análise.

No caso da deficiência visual, a diferença nas direções das odds ratios dos modelos estimados para homens e mulheres é observada para a probabilidade de procurar emprego. Entre as mulheres com limitações das atividades, aquelas que possuem essa característica têm maiores chances de procurar emprego (NE NT P) e de estudar e procurar emprego (E NT $\mathrm{P})$, enquanto, entre os homens, aqueles que possuem tal deficiência apresentam menores chances, em relação a não trabalhar, não estudar e não procurar emprego (categoria base), do que um homem que não possui deficiência visual. Resultado semelhante é observado para a probabilidade de procurar emprego dos deficientes visuais sem limitações das atividades.

\section{Conclusões}

Neste estudo foram estimadas as probabilidades de estudar/trabalhar/ procurar emprego dos jovens com idade entre 15 e 24 anos que possuem deficiência intelectual, física, auditiva e visual, através de um modelo logit multinomial e dados da PNS de 2013. De maneira geral, a deficiência pode afetar essas probabilidades se houver discriminação ou se a condição de saúde do indivíduo dificulta ou impede a execução de uma tarefa ou ação, denominada de limitações da atividade.

Em termos gerais, os resultados indicaram que a deficiência contribui para diminuir a educação e o trabalho dos jovens, o que evidencia a necessidade de maiores esforços em termos de políticas públicas para promover a participação econômica e social dessa população. As exceções a esse resultado geral são uma evidência de que as políticas de educação especial e de cotas de emprego para pessoas com deficiência alcançam de forma diferenciada as categorias dessa condição, o que sugere a necessidade de políticas específicas para cada grupo.

Um exemplo de ações específicas, voltadas para atender as necessidades de uma determinada categoria de deficiência, são os cursos de qualificação profissional desenvolvidos pelo Instituto Benjamin Constant para pessoas com deficiência visual. Categoria essa que apresentou os melhores resulta- 
dos em termos de acesso à educação e de inserção no mercado de trabalho.

Já os jovens com deficiência intelectual, com e sem limitações das atividades habituais, são os que enfrentam maiores dificuldades de inserção. Nesse caso, além das políticas específicas para atender as demandas desse grupo, também seriam importantes campanhas direcionadas à população em geral sobre preconceito e adaptações necessárias para a inclusão de pessoas com deficiência intelectual, uma vez que a dificuldade de inserção desse grupo, geralmente, está associada à discriminação e à falta de informação.

Os jovens com deficiência física que não possuem limitação se inserem com maior facilidade no mercado de trabalho, o que pode estar associado ao fato de o empregador considerar mais apropriado contratar uma pessoa com deficiência física sem limitações das atividades habituais e, assim, cumprir as determinações da política de cotas de contratação de pessoas com deficiência, sem que sejam necessários ajustes significativos nas rotinas de trabalho. Esse resultado é uma evidência de que existe seletividade na contratação de pessoas com deficiência, com priorização do deficiente físico sem limitações, em detrimento dos demais.

É importante ressaltar ainda que, nos níveis mais elevados de severidade, nos quais a pessoa realmente não possa trabalhar, as transferências do governo são de extrema importância para evitar o empobrecimento do indivíduo e da sua família. Nos demais casos, talvez poderia ser fornecido um adicional de renda condicionado aos gastos com saúde e aquisição de equipamentos, como próteses, cadeiras de roda, aparelhos aditivos etc. Tais transferências também poderiam ser condicionadas ao investimento em educação e capacitação profissional como uma forma de motivação para que a pessoa possa avançar e progredir de maneira autônoma e independente, uma vez que, em alguns casos, a dificuldade de inserção no mercado de trabalho está associada a menor qualificação.

\section{Referências}

ACEMOGLU, D.; ANGRIST, J. D. Consequences of Employment Protection? The Case of the Americans with Disabilities Act. Journal of Political Economy, v. 109, n. 5, pp. 915-957, Oct. 2001.

AMIRALIAN M. L. T.; PINTO, E. B.; GHIRARDI, M. I. G.; LICHTIG, I.; MASINI, E. F. S.; PASQUALIN, L.. Conceituando deficiência. Revista de Saúde Pública, 34 (1): 97-103, 2000.

BECKER, G. Human Capital: A Theoretical and Empirical Analysis, with Special Reference to 
Education. $3^{\text {rd }}$ ed. Chicago: University of Chicago Press, 1993.

BECKER, K. L. (2019). Deficiência, emprego e salário no mercado de trabalho brasileiro. Estudos Econômicos. São Paulo, v. 49 n. 1, p. 39-64, jan./mar. 2019.

BELL, D.; HeITMUELLER, A. (2009). The Disability Discrimination Act in the UK: Helping or hindering employment among the disabled? Journal of Health Economics. Volume 28 (2009) 465-480.

BRASIL. Lei n 8.213 de 24 de julho de 1991. Dispõe sobre os Planos de Benefícios da Previdência Social e dá outras providências. Diário Oficial [da] República Federativa do Brasil, Brasília, DF, 25 jul. 1991.

BRASIL. Decreto n 3.298 de 20 de dezembro de 1999. Regulamenta a Lei no 7.853, de 24 de outubro de 1989, dispõe sobre a Política Nacional para a Integração da Pessoa Portadora de Deficiência, consolida as normas de proteção, e dá outras providências. Diário Oficial [da] República Federativa do Brasil, Brasília, DF, 20 dez. 1999.

BRASIL. Decreto $n^{\circ} 3.956$, de 8 de outubro de 2001. Promulga a Convenção Interamericana para a Eliminação de Todas as Formas de Discriminação contra as Pessoas Portadoras de Deficiência. Guatemala, 1999. Diário Oficial [da] República Federativa do Brasil. Brasília, DF, 08 out. 2001.

BRASIL. Política Nacional de Educação Especial na Perspectiva da Educação Inclusiva. Ministério da Educação. Secretaria de Educação Especial. Brasília: MEC/SEESP, 2008.

BRASIL. Decreto n 6.949, de 25 de agosto de 2009. Promulga a Convenção Internacional sobre os Direitos das Pessoas com Deficiência. Diário Oficial [da] República Federativa do Brasil, Brasília, DF, 25 ago. 2009.

BRASIL. Decreto n 7.611, de 17 de novembro de 2011. Dispõe sobre a educação especial, o atendimento educacional especializado e dá outras providências. Diário Oficial [da] República Federativa do Brasil, Brasília, DF, 17 nov. 2011.

BRASIL. Lei n ${ }^{\circ}$ 13.146, de 6 de julho de 2015. Institui a Lei Brasileira de Inclusão da Pessoa com Deficiência (Estatuto da Pessoa com Deficiência). Diário Oficial [da] República Federativa do Brasil, Brasília, DF, 6 jul. 2015a.

BRASIL. Instituto Nacional de Estudos e Pesquisas Educacionais Anísio Teixeira. Plano Nacional de Educação PNE 2014-2024: Linha de Base. Brasília, DF: Inep, 2015b. 404 p.: il.

BRASIL. Instituto Nacional de Estudos e Pesquisas Educacionais Anísio Teixeira. Relatório do $1^{\circ}$ ciclo de monitoramento das metas do PNE: biênio 2014-2016. Brasília, DF: Inep, 2016.

CAMARANO, A. A.; KANSO, S. O que estão fazendo os jovens que não estudam, não trabalham e não procuram trabalho? Boletim de Mercado de Trabalho - Conjuntura e Análise, n. 53, Rio de Janeiro, nov. 2012. (Nota Técnica).

CASTRO, S. S.; CÉSAR, C. L. G.; CARANDINA, L.; BARROS, M. B. A.; ALVES, M. C. G. P.; GOLDBAUM, M. Deficiência visual, auditiva e física: prevalência e fatores associados em estudo de base populacional. Cadernos de Saúde Pública, Rio de Janeiro, 24(8):1773-1782, ago. 2008.

CASTRO, N. R.; MOREIRA, G. C.; SILVA; R. P. (2017). Wage Differential and Disability in Brazil - A Productive or Discriminatory Effect? In: ENCONTRO NACIONAL DE ECONOMIA, Natal, Rio Grande do Norte. Anais... Natal: Anpec, dez. 2017. 
CHARLTON J. Nothing about Us without Us: Disability, Oppression and Empowerment. Berkeley: University of California Press, 1998.

COSTA, J. S.; BECKER, K. L.; PAVÃO, A. R. Influência da renda domiciliar per capita na alocação do tempo dos jovens no Brasil. Revista de Economia, Curitiba, v. 39, p. 7-24, 2013.

CUNHA, F.; HECKMAN, J.; LOCHNER, L.; MASTEROV, D. Interpreting the Evidence on Life Cycle Skill Formation. Handbook of the Economics of Education, v. 1, p. 697-812, 2006.

FILMER D. Disability, Poverty, and Schooling in Developing Countries: Results from 14 Household Surveys. The World Bank Economic Review, 2008, 22:141-163.

HANUSHEK, E. A.; KAIN, J. F.; RIVKIN, S, G. (2002). Inferring Program Effects for Special Populations: Does Special Education Raise Achievement for Students with Disabilities? The Review of Economics and Statistics, 84(4): 584-599, Nov. 2002.

HOFFMANN, R. (2010). Como aposentadorias e pensões afetam a educação e o trabalho de jovens do domicílio. Economia e Sociedade, Campinas, v. 19, n. 1 (38), p. 201-209, abr. 2010.

IBGE (2014). Pesquisa Nacional de Saúde - PNS 2013: percepção do estado de saúde, estilos de vida e doenças crônicas. Rio de Janeiro, RJ, Brasil: Instituto Brasileiro de Geografia e Estatística (IBGE), 2014.

JONES, M. K. Disability and the Labour Market: A Review of the Empirical Evidence. Journal of Economic Studies, v. 35 Iss. 5, pp. 405-424, 2008.

JONES, M. K.; LATREILLE, P. L.; SLOANE, P. J. Disability, Gender, and the British Labour Market. Oxford Economic Papers, New Series, v. 58, n. 3, pp. 407-449, Jul. 2006.

MARTINS, D. A.; LEITE, L. P.; LACERDA, C. B. F. Políticas públicas para acesso de pessoas com deficiência ao ensino superior brasileiro: uma análise de indicadores educacionais. Ensaio: Avaliação e Políticas Públicas em Educação, Rio de Janeiro, v. 23, n. 89, p. 984-1014, out./dez. 2015.

MELETTI, S. M. F.; BUENO, J. G. S. O impacto das políticas públicas de escolarização de alunos com deficiência: uma análise dos indicadores sociais no Brasil. Linhas Críticas, Brasília v. 17, n. 33, maio-ago., pp. 367-383, 2011.

MELETTI, S. M. F.; RIBEIRO, K. (2014). Indicadores educacionais sobre a educação especial no Brasil. Cadernos Cedes, Campinas, v. 34, n. 93, p. 175-189, maio-ago. 2014.

MENDES, E. G. Breve histórico da educação especial no Brasil. Revista Educación y Pedagogía. v. 22 , n. 57 , mayo-ago. 2010.

MENEZES-FILHO, N. A.; CABANAS, P. H. F.; KOMATSU, B. K. (2014). Crescimento da renda e as escolhas dos jovens entre os estudos e o mercado de trabalho. In: ENCONTRO NACIONAL DE ECONOMIA, 42, 2014, Natal, Rio Grande do Norte. Anais... Natal: Anpec, dez. 2014.

NERI, M. Retratos da deficiência no Brasil. Rio de Janeiro: FGV/IBRE, Centro de Políticas Sociais - CPS, 2003. 250 p.

OMS World report on disability 2011. World Health Organization - WHO. Press, 20 Avenue Appia, 1211 Geneva 27, Switzerland, 2011.

OMS How to Use the ICF: A Practical Manual for Using the International Classification of Functioning, Disability and Health (ICF). Exposure Draft for Comment. Oct. 2013. World 
Health Organization. Geneva: WHO, 2013.

REIS, M. C.; CAMARGO, J. M. Impactos de aposentadorias e pensões sobre a educação e a participação dos jovens na força de trabalho. Pesquisa e Planejamento Econômico, Rio de Janeiro, v. 37, n. 2, ago. 2007.

RIBEIRO, M. A.; CARNEIRO, R. A inclusão indesejada: as empresas brasileiras face à lei de cotas para pessoas com deficiência no mercado de trabalho. Organizações \& Sociedade, Salvador, v. 16, n. 50, jul. 2009.

SCHWOCHAU, S.; BLANCK, P. D. Economics of the Americans with Disabilities Act, Part III: Does the ADA Disable the Disabled. Berkeley Journal of Employment \& Labor law. v. 21:271, 2000.

VIEIRA, C. S.; CABANAS, P.; MENEZES-FILHO, N.; KOMATSU, B. K. (2016). Como as mudanças no trabalho e na renda dos pais afetam as escolhas entre estudo e trabalho dos jovens? Pesquisa e Planejamento Econômico, PPE, v. 46, n. 3, dez. 2016.

WERNECK, C. (2004). Modelo médico x Modelo social da deficiência. Manual da mídia legal 3: comunicadores pela saúde/Escola de Gente. Rio de Janeiro: WVA Editora, 2004, p. 16-20.

\section{Sobre a autora}

Kalinca LéiaBecker-kalincabecker@gmail.com

Universidade Federal de Santa Maria, Santa Maria, Rio Grande do Sul, Brasil.

ORCID: https://orcid.org/0000-0002-6896-9411.

\section{Sobre o artigo}

Recebido em 30 de abril de 2017. Aprovado em 12 de abril de 2018. 